\title{
Influence of high-pressure gaseous hydrogen on the low-cycle fatigue and fatigue crack growth properties of a cast titanium alloy
}

\author{
R. Gaddam ${ }^{\mathrm{a}, 1}$, M. Hörnqvist ${ }^{\mathrm{b}, 2}, \mathrm{M}-\mathrm{L}$. Antti ${ }^{\mathrm{a}}$ R. Pederson ${ }^{\mathrm{a}}$ \\ ${ }^{a}$ Division of Materials Science, Luleå University of Technology, S-97187 Luleå, Sweden \\ ${ }^{b}$ Department of Applied Physics, Chalmers University of Technology, S-41296 Göteborg, Sweden
}

\begin{abstract}
In the present study, the effect of gaseous hydrogen on the fatigue properties of a commonly used aerospace titanium alloy (Ti-6Al-4V) was studied. The low-cycle fatigue and fatigue crack growth properties were investigated at room temperature in ambient air and $15 \mathrm{MPa}$ gaseous hydrogen. Results showed that the low-cycle fatigue life was significantly reduced in hydrogen, and the detrimental effect was larger at higher strain amplitudes. The fatigue crack growth rate in hydrogen remained unaffected below a critical stress intensity $\Delta K^{*} \approx 17 \mathrm{MPa} \sqrt{\mathrm{m}}$, while beyond this value, the fatigue crack growth rate fluctuated and increased with increasing $\Delta K$. Fractography analysis clearly showed that gaseous hydrogen mainly affected the fatigue crack growth rate. On the fracture surfaces, striations were noted over the entire crack growth region in air, whereas in hydrogen striations were noted at stress intensities lower than $\Delta K^{*}$. Above $\Delta K^{*}$, secondary cracks and brittle flat surfaces with features similar to crack arrest marks were mostly observed in hydrogen. Microstructural analysis along the crack growth direction showed that the crack followed a transgranular path in air, i.e. through $\alpha$ colonies. In hydrogen, the crack also grew along the prior $\beta$ grain boundaries and at $\alpha / \beta$ interface within the $\alpha$ colonies. Thereby, the detrimental effect of hydrogen in cast titanium alloy was attributed to a change in the fracture process during crack propagation.
\end{abstract}

Keywords: Titanium alloys, Fatigue, Fracture, Hydrogen embrittlement, Mechanical characterisation, Electron microscopy.

\footnotetext{
${ }^{1}$ Present address: AB Sandvik Materials Technology, SE-811 81 Sandviken, Sweden

${ }^{2}$ Corresponding author: magnus.hornqvist@chalmers.se, +46 760293084
} 


\section{Introduction}

Titanium alloy, Ti-6Al-4V is widely used in aerospace applications because of its high strength-to-weight ratio and good combination of strength and fatigue resistance up to $300^{\circ} \mathrm{C}[1,2]$. In applications where the material is exposed to gaseous hydrogen, there is a distinct risk of hydrogen pick-up during service. It is well documented [3] that titanium alloys, including Ti-6Al$4 \mathrm{~V}$, are susceptible to hydrogen embrittlement, which is one of the major limitations to their use in such applications. Most of the studies on the influence of hydrogen on titanium alloys were conducted by pre-charging with certain quantities of hydrogen, whereas rather few studies have been performed in gaseous hydrogen [4-13]. Some of these studies [4-10] showed that the mechanical properties, such as fracture toughness and fatigue properties are reduced. Others [1113] showed that gaseous hydrogen did not have any effect on the fatigue crack growth resistance of Ti-6Al-4V. Most of these investigations were performed in low-pressure hydrogen, typically below $0.1 \mathrm{MPa}$ and at higher cyclic frequencies. In a recent study [10], it was reported that the fatigue crack growth rate of forged $\mathrm{Ti}-6 \mathrm{Al}-4 \mathrm{~V}$ in high-pressure hydrogen gas was altered above a critical stress intensity $\left(\Delta K^{*}\right)$, beyond which the fracture process and the crack growth rate changed. The study suggested that $\Delta K^{*}$ could depend on the combination of testing conditions (such as the hydrogen pressure, cyclic frequency and stress ratio), microstructure and manufacturing route of the material. This could provide one explanation for the discrepancies between previous studies, as the combination of environment and testing parameters differed significantly.

It has been found that the interaction between hydrogen and titanium around the crack tip plays a major role $[6,7,10-13]$. In addition, it has been clearly demonstrated that in $\alpha+\beta$ titanium alloys such as $\mathrm{Ti}-6 \mathrm{Al}-4 \mathrm{~V}$, the effect of hydrogen is also strongly dependent on the microstructure [4]. Materials having continuous $\beta$-phase (such as Widmanstätten structure) were more severely embrittled compared to those having a continuous $\alpha$-phase (such as equiaxed structures). This effect was attributed to the relative difference in hydrogen diffusion rates between the phases. Different hydrogen embrittlement mechanisms have been proposed to be responsible for degradation of fatigue properties in titanium alloys, and the activation of different mechanisms and their interaction can also depend on the stress intensity level [8].

The aim of the present work was to investigate the influence of high-pressure gaseous hydrogen $(15 \mathrm{MPa})$ on the low-cycle fatigue and fatigue crack growth properties of cast $\mathrm{Ti}-6 \mathrm{Al}-4 \mathrm{~V}$ with transformed $\beta$ microstructure. It will be shown that the fatigue life is significantly reduced, especially at higher strain amplitudes, which can be related to an increase in the crack propagation 
rates above a critical stress intensity factor. The increased crack growth rate is a consequence of changes in the local fracture mechanisms because of interactions with the hydrogen environment. The effect of the microstructure on the extent of hydrogen induced crack acceleration is also demonstrated.

\section{Experimental Methods}

\subsection{Materials}

The material investigated was cast titanium alloy (Ti-6Al-4V) with a chemical composition (wt.\%): Al-6.22, V-3.92, Fe-0.20, O-0.16, C-0.033, N-0.022, $\mathrm{H}-0.0014, \mathrm{Y}<0.0010$, and the rest Ti. The test specimens were machined from commercially produced rings, which were hot isostatically pressed (HIP:ed) at $899^{\circ} \mathrm{C}$ for 2 hours, followed by annealing at $843^{\circ} \mathrm{C}$ for 2 hours and then furnace cooling to below $538^{\circ} \mathrm{C}$. Fig. 1 shows the typical fully lamellar microstructure with 85 $\% \alpha$ and $15 \% \beta$. The microstructure consists of prior $\beta$ grains (with a typical size of $2-3 \mathrm{~mm}$ ) separated by grain boundary $\alpha$. The $\alpha$ colonies in the prior $\beta$ grains, in the size range $0.5-1.5 \mathrm{~mm}$, contains $\alpha$ laths with typical thicknesses of $2-3 \mu \mathrm{m}$.

\subsection{Mechanical testing}

Mechanical testing was performed in servo hydraulic test machines to examine the lowcycle fatigue and fatigue crack growth behaviour in air and gaseous hydrogen. The hydrogen atmosphere was obtained by enclosing the specimen and grips in a purpose-built autoclave, which was pressurized to $15 \mathrm{MPa}$ using hydrogen of more than $99.995 \%$ purity. The load was measured by a load cell outside the autoclave and was compensated for internal pressure and piston seal friction.

Strain controlled low-cycle fatigue tests were carried out on cylindrical specimens with a gauge length of $16 \mathrm{~mm}$ and gauge diameter of $6.3 \mathrm{~mm}$. The specimens were low-stress ground down to a surface finish of $0.2 \mu \mathrm{m}$. The strain was measured with an extensometer attached to the gauge length, and the testing was conducted according to ASTM E606 using a triangular waveform at different total strain amplitudes $\left(\Delta \varepsilon_{t} / 2\right)$, with strain ratio $\varepsilon_{\min } / \varepsilon_{\max }=0$ and frequency $0.5 \mathrm{~Hz}$. Here, the number of cycles to failure $\left(N_{f}\right)$ was defined by complete separation of the specimens.

Fatigue crack growth tests were carried out using Kb-type specimens with a rectangular cross-section ( $W \times T$, where $W$ is the specimen width and $T$ is the thickness) of $10.2 \times 4.3 \mathrm{~mm}$. A notch was created on one of the $10.2 \mathrm{~mm}$ wide faces using electric discharge machining. Before 
testing a surface crack was created from the notch by fatigue cycling at room temperature at a frequency of $10 \mathrm{~Hz}$, and propagated to an initial crack length (a) of approximately $0.5 \mathrm{~mm}$. Thereafter fatigue crack growth tests were performed according to applicable parts of ASTM E64708 and ASTM E740-03 under linear-elastic fracture mechanics conditions. A triangular waveform with a stress ratio $\sigma_{\min } / \sigma_{\max }=0$ and frequency $0.5 \mathrm{~Hz}$ was used. The crack length was monitored using direct current potential drop (PD), with PD probes attached across the crack and reference probes at the back face of the specimen, away from the cracked cross-section. The PD signal was normalised by the reference signal and translated to crack lengths using an experimentally obtained calibration function, and the corresponding fatigue crack growth rates were calculated according to the secant method in ASTM E647. The stress intensity factor range, $\Delta K$, was calculated from the deepest point of the crack according to ASTM E740 assuming a semi-circular shape of the crack:

$$
\Delta K=f \cdot \Delta \sigma \sqrt{\pi a}
$$

where

$$
f=0.663+0.128(a / T)^{2}-0.068(a / T)^{4}
$$

\subsection{Characterisation}

Scanning electron microscopy (SEM) was used to investigate the fracture surfaces of the specimens after the low-cycle fatigue and fatigue crack growth testing. It was performed using secondary electrons with accelerating voltages of $3 \mathrm{kV}$ and $15 \mathrm{kV}$ in JEOL JSM-6460LV and field emission scanning electron microscope $\left(M E R L I N^{\circledR}\right)$ from Carl Zeiss. Optical microscopy was used to observe the microstructure along the fatigue crack path. Crack path profiles were prepared by protecting the fracture surface using Lacquer from METACOAT $^{\circledR}$, then cross sectioning the samples along the crack growth direction and examining from the side surface. Metallographic sample preparation was done using conventional techniques for titanium alloys, involving grinding, polishing, and etching using Kroll's reagent.

\section{Results}

\subsection{Low-cycle fatigue}

The low-cycle fatigue life of cast $\mathrm{Ti}-6 \mathrm{Al}-4 \mathrm{~V}$ was significantly lowered in gaseous hydrogen, as illustrated in Fig. 2(a), and the detrimental effect increased with increasing strain amplitude. Fig. 2(b) shows the corresponding reduction in fatigue life as a function of applied strain amplitude. The reduction is approximately constant above around $0.5 \%$, with only about $20 \%$ of the life remaining. There are no significant effects of hydrogen on the cyclic stress-strain curve $(\Delta \sigma / 2$ vs $\left.\Delta \varepsilon_{t} / 2\right)$ obtained from the mid-life cycles, as shown in Fig. 3(a), other than the larger scatter. 
However, a closer examination of the stress amplitude development revealed subtle differences between the tests in air and hydrogen. While the initial stress amplitude development at high strain amplitudes was similar in air and hydrogen, there was a more rapid decrease towards the end of the fatigue life in the specimens tested in hydrogen (see Fig. 3(b)). No distinct difference in the stress amplitude development could be seen at lower strain amplitudes. Here it should be noted that the gradual increase in the stress levels at the beginning of one of the $1 \%$ tests in air is not a material effect, but is due to non-optimal control settings of the testing machine, resulting in a gradual increase in the applied $\Delta \varepsilon_{t} / 2$ until the target amplitude $1 \%$ is reached after about 10 cycles.

SEM investigations of the fracture surfaces of specimens tested in air and gaseous hydrogen revealed that the crack initiation (denoted as I in Fig. 4(a) and 4(b)) has taken place at the surface in both air and gaseous hydrogen. However, it was difficult to distinguish a particular feature responsible for the crack initiation. The noticeable difference was found in the fatigue crack growth region. Striations were observed over the entire crack growth region in air (see Fig. 4(c)), whereas in hydrogen the striations were only seen at short crack lengths. At longer crack lengths secondary cracks and brittle flat surfaces with features like crack arrest marks (see Fig. 4(d)) dominated the fracture surface in hydrogen. Similar changes in the fracture surfaces as a function of crack length were also noted on the specimens tested at lower strain amplitude in hydrogen. The final fracture in air consisted of dimples from ductile tearing (Fig. 4(e)). Dimples were also observed in the final fracture region of the specimens tested in hydrogen, but the dimples were much smaller and the ductile tearing was intermixed with regions of brittle fracture (Fig. 4(f)). In air, the crack followed a transgranular path, i.e. through the $\alpha$ lamellas present in the $\alpha$ colonies, which can be clearly seen in the crack path profiles in the cross-sections in Fig. 5(a). In contrast, in the presence of hydrogen the crack followed both transgranular and intergranular paths. The primary crack propagated through the $\alpha$ colonies, along the prior $\beta$ grain boundaries and at $\alpha / \beta$ interface within the $\alpha$ colonies (see Fig. $5(\mathrm{~b})$ ). Furthermore, in hydrogen there were secondary cracks that followed a similar path as the primary crack. The behaviour described above was common for all tested strain amplitudes.

\subsection{Fatigue crack growth}

Fig. 6(a) shows the fatigue crack growth curves obtained in air and gaseous hydrogen. The fatigue crack growth rate in air approximately followed a power law relationship for the tested stress intensity factor ranges. Initially the fatigue crack growth rate in gaseous hydrogen was almost identical to the one in air, but then it started to fluctuate and accelerated significantly with increasing $\Delta K$. The fluctuations can also be observed in Fig. 6(b), indicating an unstable crack 
growth. The extent of the hydrogen effect was evaluated by dividing the fatigue crack growth rate in hydrogen by the rate in air (see Fig. 7). For this purpose a Paris exponential law

$$
\frac{d a}{d N}=C \Delta K^{m}
$$

was fitted to the $\mathrm{d} a / \mathrm{d} N$ vs. $\Delta K$ curve in air (see Fig. 6(a)), and the effect of hydrogen was calculated as

$$
\frac{(d a / d N)_{H y d r o g e n}^{i}}{(d a / d N)_{A i r}^{i}}=\frac{(d a / d N)_{H y d r o g e n}^{i}}{C \Delta K_{i}^{m}}
$$

where $\Delta K_{i}$ and $(\mathrm{d} a / \mathrm{d} N)_{H y d r o g e n}^{i}$ are the stress intensity factor range and crack growth rate for the $i^{\text {th }}$ data point in hydrogen. In Fig. 7, the fatigue crack growth curve can be divided into two distinct areas. In the first region, $\mathrm{A}(\Delta K \leq 17 \mathrm{MPa} \sqrt{\mathrm{m}})$, the fatigue crack growth rate was unaffected by hydrogen and showed a stable crack growth similar to the one in air. In the second region, B $(\Delta K>17 \mathrm{MPa} \sqrt{\mathrm{m}})$, the average fatigue crack growth rate in hydrogen was higher than in air. The $\mathrm{d} a / \mathrm{d} N$ values fluctuate significantly, and reached levels as much as two orders of magnitude higher than in air.

Macroscopic views of the fracture surfaces of the fatigue crack growth tested specimens are shown in Fig. 8(a) and Fig. 8(b), where the effect of the coarse grained as-cast structure is reflected in the crack shapes. Further, SEM examinations showed that the fracture surfaces in air contained striations along the entire surface (see Fig. 8(c)). In contrast, the specimens tested in hydrogen showed significant differences in different areas of the fracture surface, corresponding to the regions $\mathrm{A}$ and $\mathrm{B}$ shown in Fig. 7. In region A $(a \leq 0.75 \mathrm{~mm})$, the fracture surface consisted of fatigue striations (see Fig. 8(d)) similar to those seen in air. In region B $(a \geq 0.75 \mathrm{~mm})$, the fracture surface consisted of relatively flat areas with the features resembling crack arrest marks along with secondary cracks (see Fig. 8(e)). With an increasing crack length the fracture surface became dominated by brittle fracture areas with secondary cracks (see Fig. 8(f)).

Fig. 9 shows representative micrographs of the crack path profiles from fatigue crack growth specimens corresponding to region B in Fig. 7. In air the crack growth was transgranular, passing through the $\alpha$ lamellas within $\alpha$ colonies (see Fig. 9(a)). The crack path in hydrogen followed similar paths as noted in low-cycle fatigue specimens, i.e. mixed transgranular and intergranular paths (see Figs. 9(b-c)). In addition, secondary cracks about 50-200 $\mu \mathrm{m}$ in depth were observed. These extend from the fracture surface, mostly following $\alpha / \beta$ interfaces.

\section{Discussion}




\subsection{Effect of hydrogen on the fatigue properties}

Results of the present study show that $15 \mathrm{MPa}$ gaseous hydrogen reduces the low-cycle fatigue life and increases the fatigue crack growth rate in cast Ti-6Al-4V. The reduction in lowcycle fatigue life due to hydrogen increased with increasing applied strain amplitude. This can be explained by the increased crack growth rates seen in the fatigue crack growth tests, as crack growth will constitute a larger part of the fatigue life at higher strain amplitudes. At lower strain amplitudes, i.e. in the elastic regime, the majority of the fatigue life is spent in the crack initiation phase, and an increase in the fatigue crack growth rate will not have a significant impact on the total fatigue life. In the typical low-cycle fatigue regime, on the other hand, a large plastic strain lead to early crack initiation, and the majority of the fatigue life is spent propagating these cracks to failure. Furthermore, the rapid reduction in stress amplitude towards the end of the fatigue life of the specimens tested in hydrogen, which is related to the loss of the load bearing area in the crack plane, also suggests that the increased fatigue crack growth rate plays a significant role in the life reduction.

The observations above also indicate that crack initiation is not significantly affected by the presence of hydrogen. Further support for this can be found from the investigations of the fracture surfaces. No effect of hydrogen could be seen on the fracture surfaces for short crack lengths in the low-cycle fatigue specimens, or at low $\Delta K$ in the fatigue crack growth specimens, where ductile striations were seen in both air and hydrogen. These observations suggest that hydrogen related damage mechanisms were not very active in the early stages of the fatigue life. Only above a critical stress intensity factor range, $\Delta K^{*}=17 \mathrm{MPa} \sqrt{\mathrm{m}}$, an increase in the fatigue crack growth rate could be observed in hydrogen, accompanied by a change in the fracture surface features. In order to compare the observed transition in fracture mechanisms in the low-cycle fatigue specimens to the estimated $\Delta K^{*}$ from the fatigue crack growth tests, the crack lengths corresponding to the transition from striations to hydrogen affected crack growth were measured from the fracture surfaces. Specimens from all strain ranges were investigated, and the obtained crack lengths were converted to stress intensity factors using the following expression for a surface crack in a solid cylinder of diameter $D$ [14]:

$$
\Delta K=g(a / D) \Delta \sigma \sqrt{\pi a}
$$

where

$$
\begin{aligned}
& g=G \cdot\left(0.752+1.286 \beta+0.37[1-\sin \beta]^{3}\right) \\
& G=0.92 \frac{2}{\pi} \sec \beta \sqrt{\frac{\tan \beta}{\beta}} \\
& \beta=\frac{\pi}{2} \frac{a}{D}
\end{aligned}
$$


Assuming that crack closure occurs at zero stress, the maximum stress at half-life was used in the calculation $\left(\Delta \sigma=\sigma_{\max }\right)$. The $\Delta K^{*}$ values calculated for the low-cycle fatigue specimens range from 17.4 to $20.9 \mathrm{MPa} \sqrt{\mathrm{m}}$, with an average of $19.1 \mathrm{MPa} \sqrt{\mathrm{m}}$ and showed no systematic dependence on the applied strain range (see Table 1). Finite element calculations have shown that crack closure under large scale yielding conditions, as in the present low-cycle fatigue tests, occur at slightly positive stresses $[15,16]$. For stress ratios $-1 \leq R \leq 0$ and plane strain conditions, crack opening occurred between zero and $20 \%$ of the maximum stress [15]. For surface cracks this has also been verified experimentally, with measured opening levels around $10 \%$ of maximum load for $-1 \leq R \leq 0$ [17]. Taking this into account, one can set $\Delta \sigma=0.9 \sigma_{\max }$, which results in an average $\Delta K^{*}$ of 17.2 $\mathrm{MPa} \sqrt{\mathrm{m}}_{\mathrm{m}}$ (see Table 1). Considering the uncertainties, the values obtained are in accordance with the observations of $\Delta K^{*}=17-18 \mathrm{MPa} \sqrt{\mathrm{m}}$ from the fatigue crack growth specimens, indicating that it is likely that the effect of gaseous hydrogen on the low-cycle fatigue life is a result of the rapid crack growth, which sets in after the critical stress intensity factor is reached.

Similar observation regarding the existence of a critical stress intensity factor for hydrogen influence was previously noted in forged $\mathrm{Ti}-6 \mathrm{Al}-4 \mathrm{~V}$ under identical test conditions [10]. In contrast, earlier studies in gaseous hydrogen showed that the fatigue crack growth rate in Ti-6Al$4 \mathrm{~V}$ was slightly reduced compared to air at room temperature [11-13]. The hydrogen pressures in the latter studies were much lower $\left(10^{-5}-0.1 \mathrm{MPa}\right)$, and at such low pressure levels the reduction in the fatigue crack growth rate may well be a result of the reduced effect of oxygen, which is outweighing the detrimental effect of the presence of small amounts of hydrogen. This explanation is supported by the similar fatigue crack growth rates obtained in vacuum and low-pressure hydrogen [13]. Fatigue crack growth studies on a duplex annealed titanium alloy (Ti-6Al-2Sn$4 \mathrm{Zr}-2 \mathrm{Mo}-0.1 \mathrm{Si}$ ), which was charged with $530 \mathrm{ppm}$ hydrogen showed that the fatigue crack growth rate was identical to the specimens up to $\Delta K^{*} \approx 20 \mathrm{MPa} \sqrt{\mathrm{m}}$ when compared to that of the as-received material containing 53 ppm hydrogen [18]. Furthermore, it was also demonstrated that the smaller cyclic frequency leads to an increase in crack growth rates at higher $\Delta K$ while similar fatigue crack growth rates were observed at lower $\Delta K$. These observations support the existence of the currently proposed critical stress intensity $\Delta K^{*}$, being a function of microstructure and testing conditions, above which the effect of hydrogen is noticed.

Another effect of hydrogen on the fatigue life could be the reduction of the fracture toughness, $K_{\mathrm{c}}$, leading to failure at shorter crack lengths for given applied stress or strain amplitude. In the present investigation the fatigue crack growth tests were interrupted before the fracture toughness was approached so no linear elastic fracture mechanics estimation of $K_{c}$ could be made. 
Furthermore, it was not possible to extract a conclusive crack length corresponding to the onset of final failure of the low-cycle fatigue specimens. Therefore, no conclusions can be drawn in this respect, but rough estimates from the crack surfaces indicate no systematic effect of hydrogen on the crack length where final fracture commences.

The applicability of $\Delta K$ as a parameter for crack growth in the present study could be questioned due to the coarse microstructure. The coarseness results in a crack shape that does not comply with the semi-circular front assumed in the calculation of the stress intensity factors. However, as the development of the crack front shape during testing was not known, it was not possible to account for the geometry in stress intensity factor calculations. Additionally, the low number of grains encountered by the crack front does not provide the necessary conditions for the assumed isotropic continuum. However, the results obtained from the tests in air show that the data fit well to the representation in terms of Paris law, which provides support for using $\Delta K$ as a crack driving force parameter despite of these objections.

\subsection{Effect of microstructure}

The effect of microstructure on the effects of hydrogen can be seen by comparing the fatigue crack growth results obtained on cast $\mathrm{Ti}-6 \mathrm{Al}-4 \mathrm{~V}$ in the present study and the previous investigation of the forged Ti-6Al-4V under identical conditions [10]. Fig. 10(a) shows that the effect of gaseous hydrogen on the crack growth is much larger for the cast material. Cast $\mathrm{Ti}-6 \mathrm{Al}-4 \mathrm{~V}$ consists of lamellar microstructure with coarse prior $\beta$ and $\alpha$ colonies (see Fig. 1(a)), where each colony is built of $\alpha$ lamellas parallel to each other. The $\beta$ phase retained (dark) in these microstructures is mostly found between the $\alpha$ lamellas and at the grain boundaries (see Fig. 1(b)). In contrast, the forged material consists of a bimodal microstructure with primary $\alpha$ and transformed $\beta$ grains. The transformed $\beta$ grains consist of $\alpha$ colonies as noted in the cast, but smaller in size. It has been shown for titanium alloys that lamellar microstructures are more susceptible to hydrogen embrittlement, as the hydrogen transport is much faster through the continuous network of $\beta$ phase $[4,19]$. In the present case, hydrogen diffuses at a higher rate and deeper into the material in cast condition due to the long and continuous network of $\beta$ phase compared to the forged material, which leads to higher fatigue crack growth rates. From Fig. 10(b), the value of $\Delta K$ above which the hydrogen effect is noticed, appears to be lower in the cast material $\left(\Delta K^{*} \approx 17 \mathrm{MPa} \sqrt{\mathrm{m}}\right.$ compared to around $20 \mathrm{MPa} \sqrt{\mathrm{m}}$ in forged), but given the low number of tests and uncertainties in the calculations of $\Delta K$ in the cast material (see discussion above) this is not conclusive.

\subsection{Crack growth mechanisms}


The present results show that the main effect of gaseous hydrogen is an increase in the fatigue crack growth rate. The analysis of low-cycle fatigue and fatigue crack growth specimens shows that the fracture surfaces in air consist of fatigue striations, and the crack follows transgranular path. In contrast, the fracture surface in gaseous hydrogen consists of striations at low $\Delta K$ (short crack lengths). At higher $\Delta K$ (longer crack lengths) crack arrest type features and brittle surfaces with secondary cracks become dominant. The changes in the fracture surface features in different regions of the fatigue crack growth specimens corresponded to the regions where the fatigue crack growth rate altered (see Fig. 7).

The striations observed at low $\Delta K$, were similar to those noted in specimens tested in air, implying that the loading conditions at the crack tip are insufficient for the hydrogen to influence the crack growth. Beyond $\Delta K^{*}$ the stress intensities are high enough to result in increasing hydrogen interaction, and two different effects of this interaction can be noted from the fracture surfaces: (i) Secondary cracks start to form, producing branching of the main crack during propagation. As such cracks are not seen in the specimens tested in air, they must be interpreted as a result of the effects of hydrogen in the crack tip region. The effect of crack branching may be an overall reduction in the fatigue crack growth rate, as the secondary $\operatorname{crack}(\mathrm{s})$ can shield the main crack tip so the driving force for crack growth is reduced [20]. (ii) The fracture surface features observed above $\Delta K^{*}$, along with the secondary cracks, are mainly similar to crack arrest marks, which are commonly termed as "terraced structures". These features are indications of crack propagation by repeated stress-induced formation and step-wise fracturing of brittle hydrides in $\alpha-\beta$ titanium alloys $[4,19]$. The increase in crack tip stresses at these stress intensities could provide sufficient conditions for the hydrogen to accumulate at the crack tip $[8,21,22]$. The accumulated hydrogen diffuses mainly through $\beta$ phase [23] and will react with $\alpha$ phase along the $\alpha / \beta$ boundaries and precipitate as brittle hydrides $[4,8,23]$. It has been shown by in-situ TEM studies of delayed cracking in hydrogen charged $\mathrm{Ti}-6 \mathrm{Al}-4 \mathrm{~V}$ (790 ppm), that crack propagation occurred through stress-induced hydride precipitation [24]. Hydrides nucleated either at the crack tip or at the boundary between the elastic and plastic zone. The crack propagated by fracturing of hydrides, by growth along the particles, or by linking of micro-cracks associated with hydrides formed some distance from the crack tip. Thus it can be expected that in the region $\mathrm{B}$, where there is a simultaneous crack branching and hydride formation there should be a competition between crack deceleration and acceleration. This may partly explain the observed fluctuations in the fatigue crack growth rate. Another factor contributing to the fluctuations could be the coarse microstructure, where the crack front only interacts with a few grains at any given time. The grain-to-grain variation in structure, and corresponding hydrogen susceptibility, may thus produce a large effect on the macroscopic response. 
At even higher stress intensities the fracture surfaces in gaseous hydrogen consist of features indicative of brittle fracture, still containing secondary cracks (see Fig. 8(f)). At these stress intensities the crack growth is rapid and might not provide enough time to form stress-induced hydrides. Instead, the hydrogen diffused into the material may result in an increase of local plastic deformation at the crack tip by enhancing the mobility of dislocations, thereby increasing the fatigue crack growth rate and resulting in brittle fracture. The term "local plastic deformation" here refers to an increased dislocation activity on an extremely local scale, which lead to a highly localised fracture. This phenomenon is commonly referred to as hydrogen enhanced localised plasticity (HELP) [8].

Similar changes in the crack growth mechanism with stress intensity were also noted on forged $\mathrm{Ti}-6 \mathrm{Al}-4 \mathrm{~V}$ [10].There it was possible to more precisely distinguish the stress intensities where the fracture mechanisms were changing. In the present study, however, this was more difficult because of the coarse microstructure. Nevertheless, the present study shows clear evidence that the fatigue crack growth behaviour is affected by high-pressure gaseous hydrogen in the same manner as suggested in [10], irrespective of the alloy condition. This can be attributed to a change in the fracture processes involved in hydrogen assisted cracking. The observed changes in dominating fracture process depending on the stress intensity factor agrees with the study by Shih et al. [8] on titanium alloy, $\mathrm{Ti}-4 \mathrm{Al}$.

During final failure the fracture surface exhibits a mix of ductile tearing (similar to the final fracture seen in air) and brittle fracture indicative of hydrogen embrittlement. One explanation could be that the crack growth is too rapid even for the HELP mechanism to occur, and thus the fracture mechanism reverts to the normal ductile failure mode. This would slow down the progress of the failure, as ductile tearing is slower than brittle cracking. At this slower deformation rate part of the microstructure may again experience conditions allowing hydrogen interactions, forming local areas of brittle fracture on the final fracture surface otherwise dominated by dimples from the ductile tearing. However, this was not investigated further in the present study.

\section{Conclusions}

Low-cycle fatigue and fatigue crack growth tests were performed on cast titanium alloy, Ti$6 \mathrm{Al}-4 \mathrm{~V}$ in air and gaseous hydrogen $(15 \mathrm{MPa})$.The results indicate that high-pressure hydrogen has a significant effect on the fatigue properties of Ti-6Al-4V and the conclusions are as follows: 
1. The low-cycle fatigue life is reduced in gaseous hydrogen compared with air. The effect is more pronounced at higher strain amplitudes. The lower fatigue life is attributed to a reduction in the number of cycles for crack growth rather than for crack initiation.

2. The fatigue crack growth rate is altered at a critical stress intensity $\Delta K^{*}$, beyond which it increases drastically. The increased fatigue crack growth rate above $\Delta K^{*}$ is a result of changes in the crack growth mechanism due to the presence of hydrogen, and the dominating mechanism depends on the stress intensity.

3. The detrimental effect of hydrogen on fatigue crack growth rate is larger in cast Ti-6Al-4V with a fully lamellar microstructure and larger $\alpha$ colonies than in forged material with bimodal structure and smaller $\alpha$ colonies.

\section{Acknowledgements}

The authors would like to acknowledge Graduate School of Space Technology at Luleå University of Technology and The Swedish Board for Innovation Systems (VINNOVA) through the National Aviation Research Programme (NFFP, grant number 2013-01150) for providing financial assistance. Dr. Johanne Mouzon is gratefully acknowledged for providing access to the high resolution scanning electron microscopy facility at the Department of Civil, Environmental and Natural Resources Engineering, Luleå University of Technology, Sweden. 


\section{References}

[1] R.R. Boyer, Mater. Sci. Eng. A 213 (1-2) (1996) 103-114.

[2] M. Peters, J. Kumpfert, C.H. Ward, C. Leyens, Adv. Eng. Mater. 5 (2003) 419-427.

[3] D. Eliezer, T. Böllinghaus, in: R.P. Gangloff, B.P. Somerday (Eds.), Gaseous hydrogen embrittlement of materials in energy technologies: The problem, its characterisation and effects on particular alloy classes, Woodhead Publishing Limited, Cambridge, United Kingdom, 2012, pp. 668-706.

[4] H.G. Nelson, D.P. Williams, J.E. Stein, Metall. Trans. 3 (1972) 469-475.

[5] M.S. Yeh, J.H. Huang, Mater. Sci.Eng. A 242 (1998) 96-107.

[6] G.F. Pittinato, Trans. ASM. 62 (1969) 410-417.

[7] G.F. Pittinato, Metall. Trans. 3 (1972) 235-243.

[8] D.S. Shih, I.M. Robertson, H.K. Birnbaum, Acta Metall. 36 (1988) 111-124.

[9] R. Gaddam, P. Åkerfeldt, R. Pederson, M-L. Antti, in: Proceedings of the $12^{\text {th }}$ World Conference on Titanium, Science Press, Beijing, People Republic of China, 2012, pp.18851888 .

[10] R. Gaddam, R. Pederson, M. Hörnqvist, M-L Antti, Corros. Sci.78 (2014) 378-383.

[11] M.R. Bache, W.J. Evans, M. McElhone, Mater. Sci.Eng. A 234-236 (1997) 918-922.

[12] W.J. Evans, M.R. Bache, M. McElhone, L. Grabowski, Int. J. Fatigue 19 (1997) S177S182.

[13] Y.S. Ding, L.W. Tsay, C. Chen, Corros. Sci. 51 (2009) 1413-1419.

[14] R.G. Forman, V. Shivakumar, in: J.H. Underwood, R. Chait, C.W. Smith, D.P. Wilhelm, W.A. Andrews and J.C. Newman (Eds.), Fracture Mechanics: $17^{\text {th }}$ Volume ASTM STP 905, ASTM International, Philadelphia, USA, 1986, pp. 59-74.

[15] R.C. McClung, H. Sehitoglu, J. Eng. Mater. Tech. 113 (1991) 15-22.

[16] R.C. McClung, H. Sehitoglu, in:J.C. Newman, Jr. and W. Elber (Eds.), Mechanics of Fatigue Crack Closure, ASTM STP 982, ASTM International, Philadelphia, USA, 1988, pp. 279-299.

[17] A.H. Rosenberger, E: Andrieu, H. Ghonem,in: S.D. Antolovich, R.W. Stusrud, R.A. MacKay, D.L. Anton, T. Khan, R.D. Kissinger, D.L. Klarstrom (Eds.), Proceedings of Superalloys 1992, TMS, Champion, PA, USA, 1992, pp. 737-746

[18] P.S. Pao, G.W. Wille, J. Nucl. Mater. 103 \&104 (1981) 931-935.

[19] H.G. Nelson, Metall. Trans. 7 (1976) 621-627.

[20] R.O. Ritchie, Mater. Sci. Eng. A 103 (1988) 15-28.

[21] W.J. Evans, M.R. Bache, Scr. Mater. 32. (1995) 1019-1024. 
[22] J.R. Kennedy, P.N. Alder, R.L. Schulte, Scr. Metall. 14 (1980) 299-303.

[23] T.P. Papazoglou, M.T. Hepworth, Trans. Met. Soc. AIME 242 (1968) 682-685.

[24] H.Z. Xiao, S.J. Gao, X.J. Wan,Scr. Metall. 21 (1987) 265-268. 
Table 1. Calculation of stress intensity factor range $(\Delta K)$ corresponding to the transition from striations to terrace-structured fracture surface in three low-cycle fatigue specimens tested in hydrogen.

\begin{tabular}{ccccccc}
\hline & & & & & \multicolumn{3}{c}{$\Delta K$} \\
\cline { 5 - 7 }$\Delta \varepsilon / 2$ & $\sigma_{\max }$ & $\Delta \sigma / 2$ & $\sigma_{\text {mean }}$ & $a$ & $\Delta \sigma=\sigma_{\max }$ & $\Delta \sigma=0.9 \sigma_{\max }$ \\
$(\%)$ & $(\mathrm{MPa})$ & $(\mathrm{MPa})$ & $(\mathrm{MPa})$ & $(\mathrm{mm})$ & $(\mathrm{MPa} \sqrt{\mathrm{m})}$ & $(\mathrm{MPa} \sqrt{\mathrm{m}})$ \\
\hline 0.9 & 798 & 792 & 7 & 0.47 & 20.9 & 18.8 \\
0.5 & 738 & 631 & 108 & 0.39 & 17.4 & 15.8 \\
0.3 & 664 & 415 & 250 & 0.55 & 19.0 & 17.1 \\
\hline
\end{tabular}



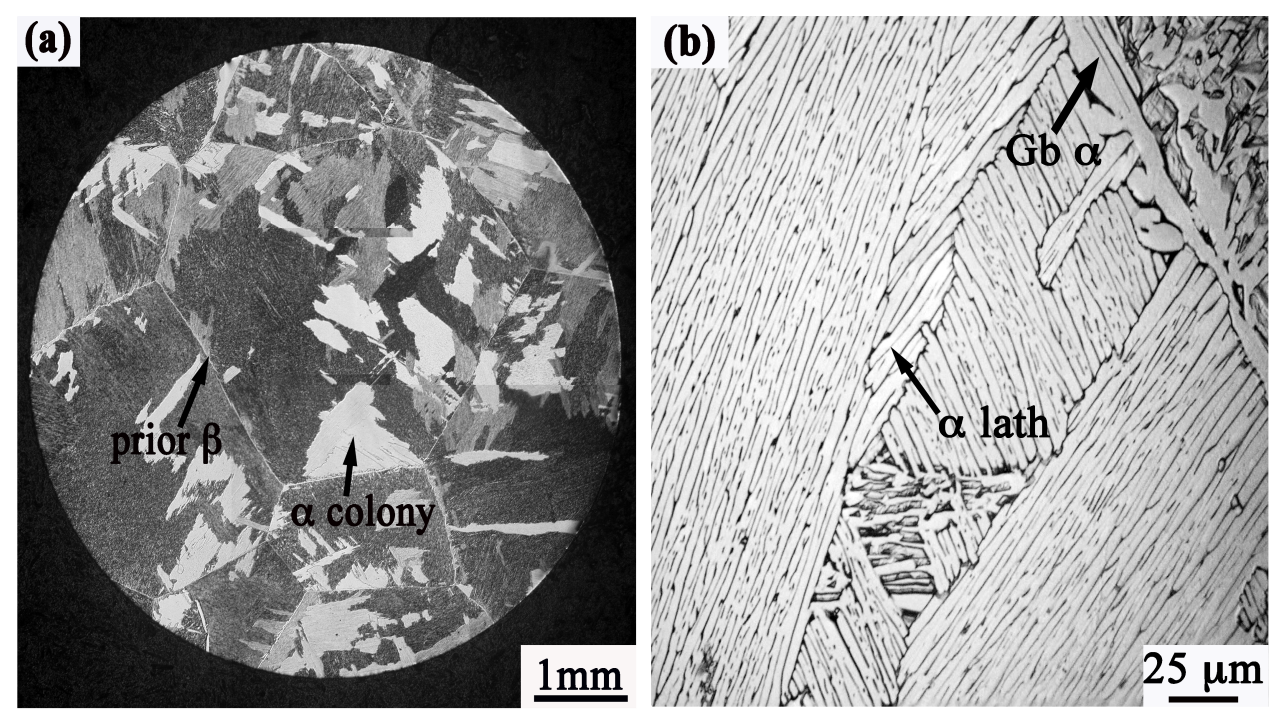

Fig. 1. Microstructure of the as-received cast Ti-6Al-4V alloy showing microstructural features: (a) prior $\beta$ grains and $\alpha$ colonies; (b) grain boundary (Gb) $\alpha$ and $\alpha$ laths.
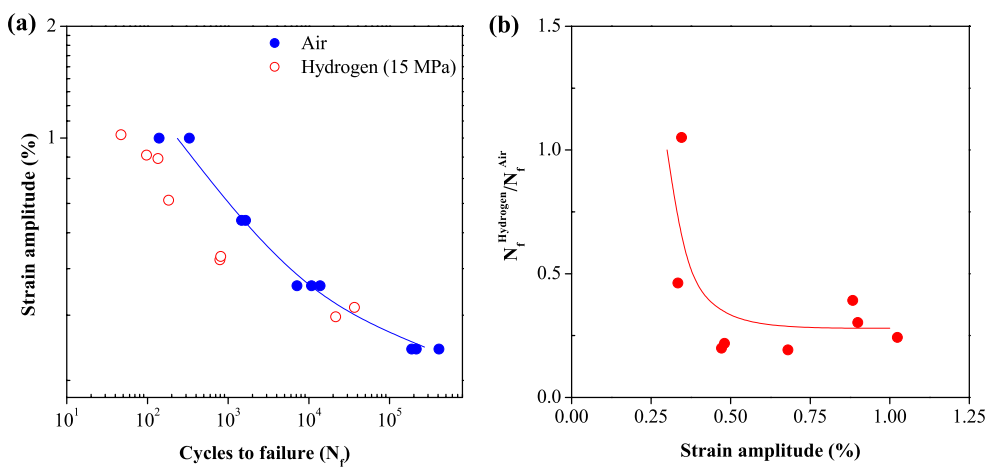

Fig. 2. (a) Low-cycle fatigue results in air and gaseous hydrogen. (b) Reduction in low-cycle fatigue life in hydrogen as a function of strain amplitude.
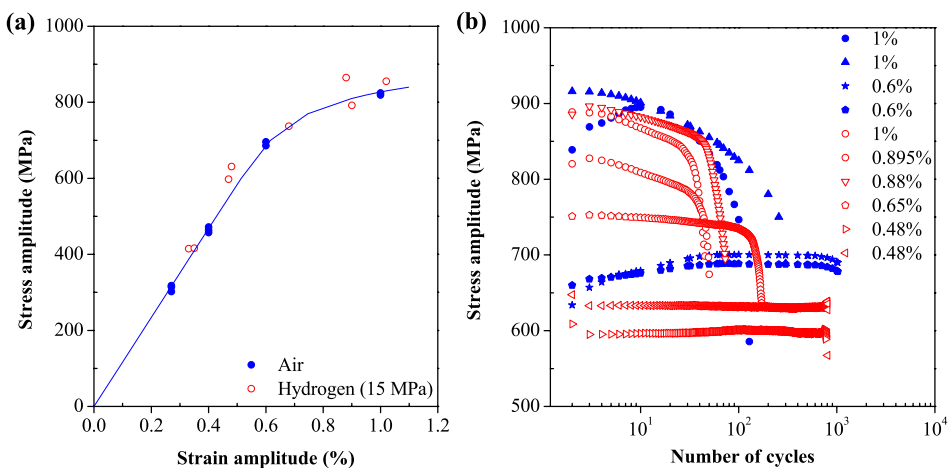

Fig. 3. (a) Cyclic stress-strain curve $\left(\Delta \sigma_{t} / 2\right.$ vs $\left.\Delta \varepsilon_{t} / 2\right)$ in air and hydrogen. (b) Stress amplitude vs. number of cycles to failure at strain amplitudes $>0.45 \%$. Solid blue data points are for air and open red data points for gaseous hydrogen (for the interpretation of references to colours in this figure legend, the reader is referred to the web version of the article). 

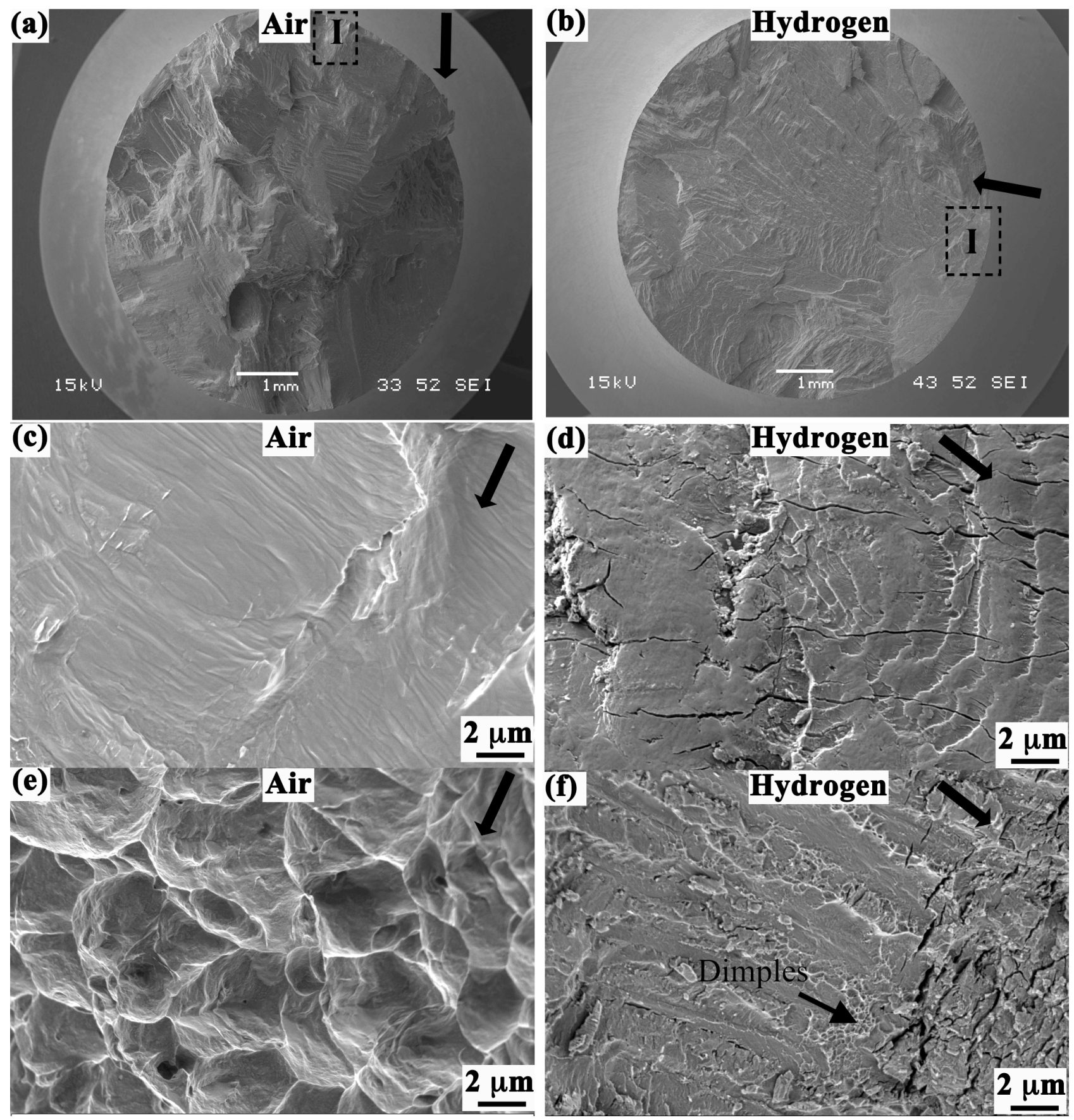

Fig. 4. Fatigue fracture surfaces observed on the low-cycle fatigue specimens that were tested at $\Delta \varepsilon_{t} / 2=1 \%$ in air and hydrogen. (a,b) Overviews of fracture surfaces in the crack initiation area (I) and $(c, d)$ representative fracture surfaces in the crack growth area. $(e, f)$ Typical features observed in the final fracture regions. Arrows indicate the direction of crack growth. 
(a) Air

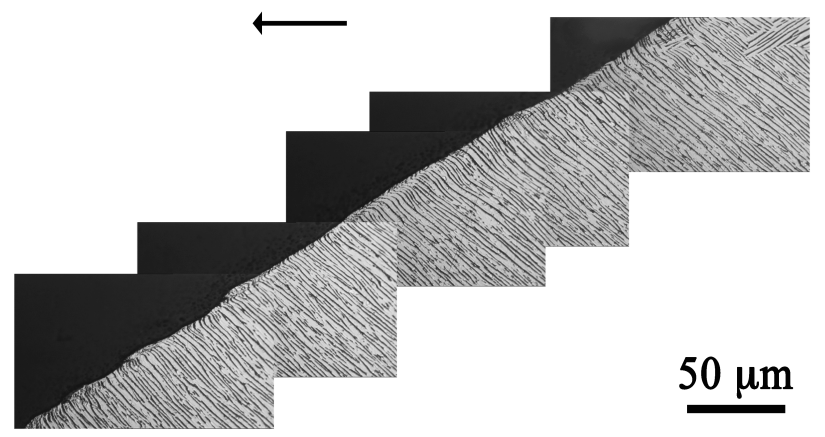

(b) Hydrogen

$50 \mu \mathrm{m}$

Fig. 5. Crack path profiles along the crack propagation area of low-cycle fatigue tested specimens in (a) air, and (b) hydrogen. The arrow indicates the direction of the fatigue crack.

(a)

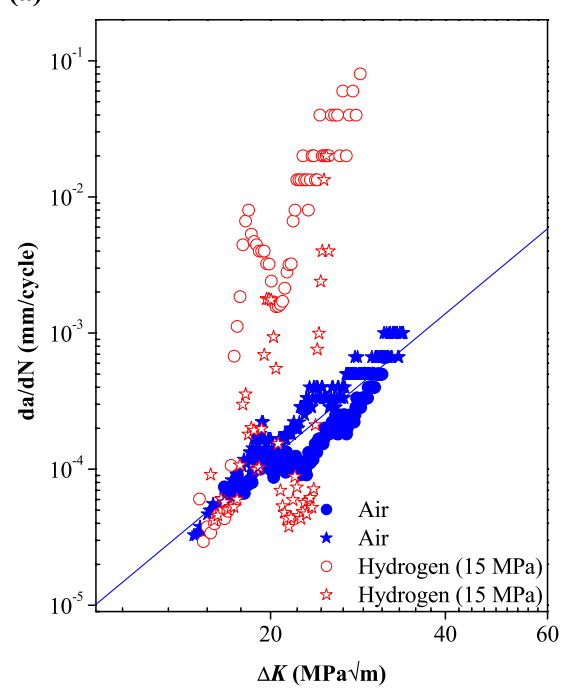

(b)

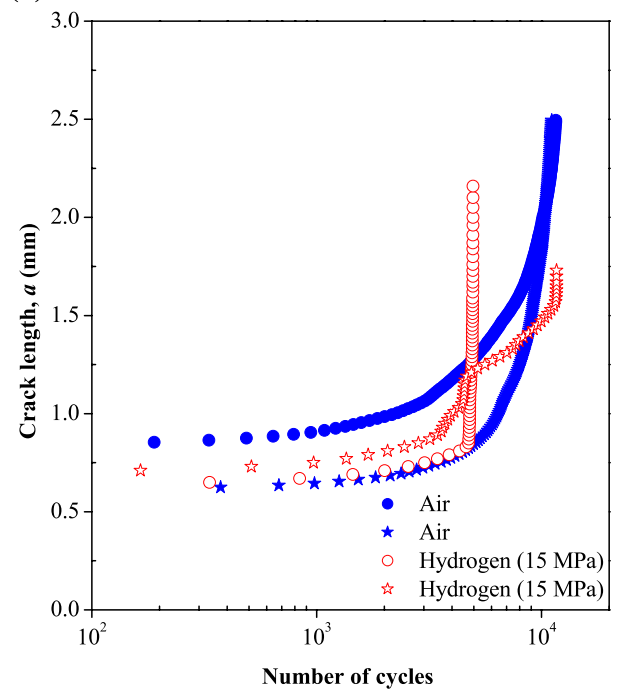

Fig. 6. Fatigue crack growth curves in air and gaseous hydrogen. (a) $\mathrm{d} a / \mathrm{d} N$ vs. $\Delta K$, and (b) crack length vs. number of cycles. In (a) the Paris fit to the air data is shown as a line. 


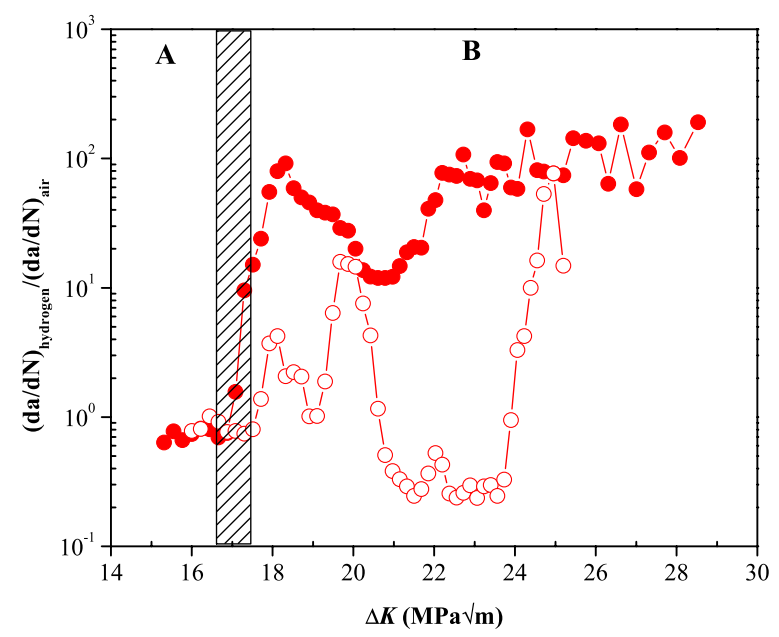

Fig. 7. The relative effect of hydrogen on fatigue crack growth rate as a function of $\Delta K$ in the two tested specimens as a function of $\Delta K$.

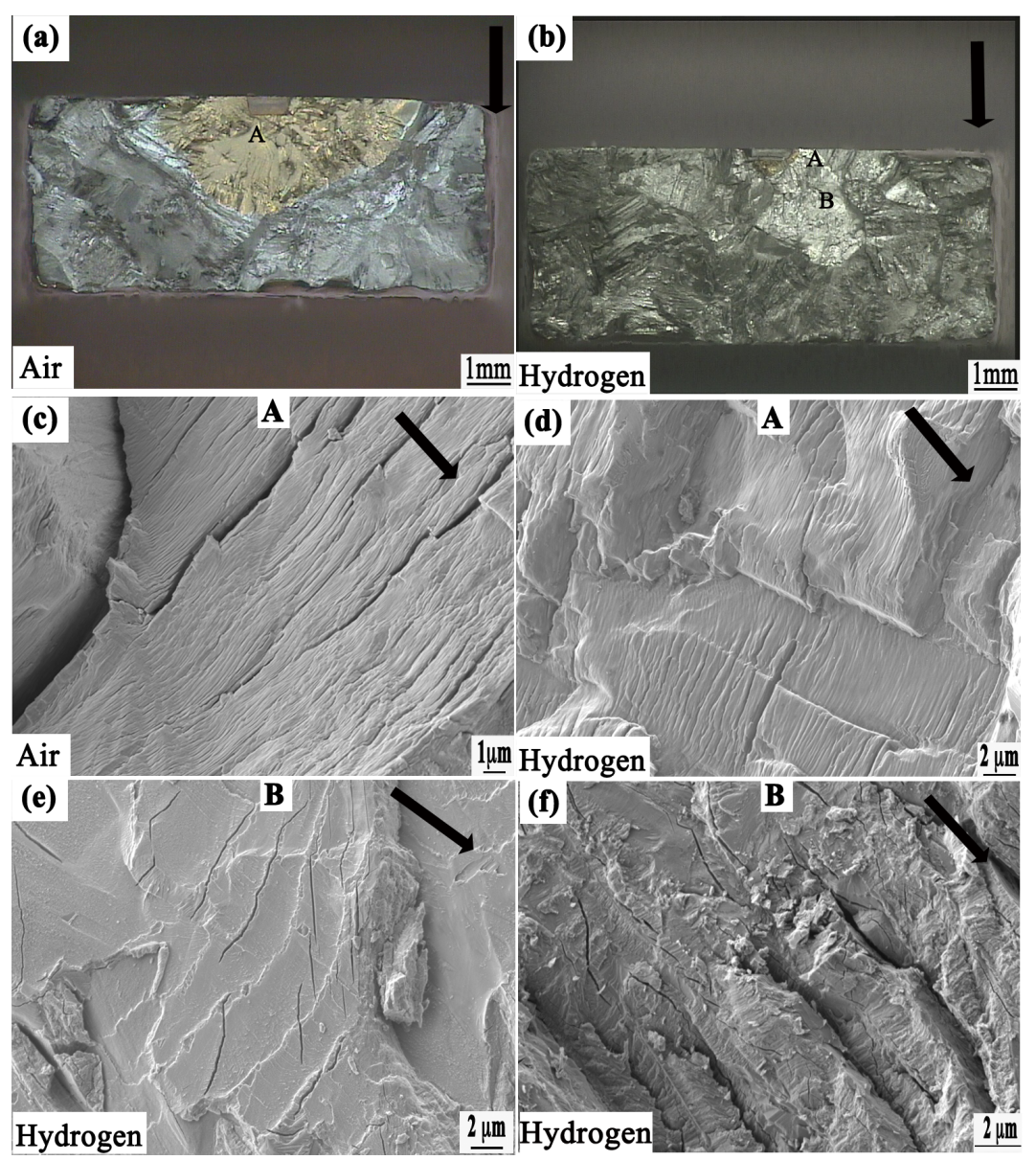

Fig. 8. Representative fatigue fracture surfaces observed in the fatigue crack growth specimens tested in air and gaseous hydrogen. (a,b) Macroscopic views. (c,d) Striations present throughout the fracture surface in air below $\Delta K \leq 17 \mathrm{MPa} \sqrt{ }$ m. (e) Brittle flat surface with features looking like crack arrest marks along with secondary cracks at $\Delta K>17 \mathrm{MPa} \sqrt{\mathrm{m}}$ in hydrogen. (f) Brittle surface with secondary cracks in hydrogen at high $\Delta K$. Arrows indicate the crack growth direction. 


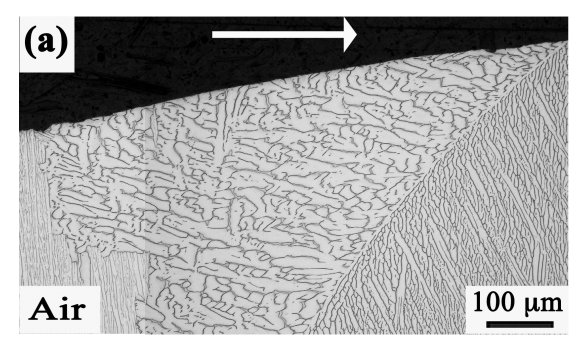

(b)

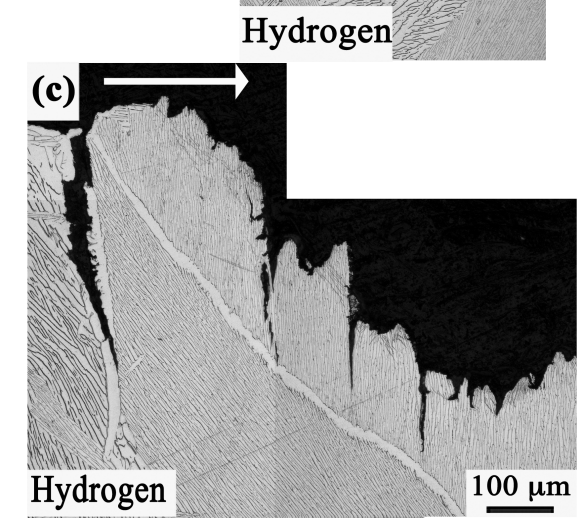

Fig. 9. Representative crack path profiles in region B along the fatigue crack growth direction. (a) Air, and $(b, c)$ hydrogen. Arrows indicate the direction of the crack growth.
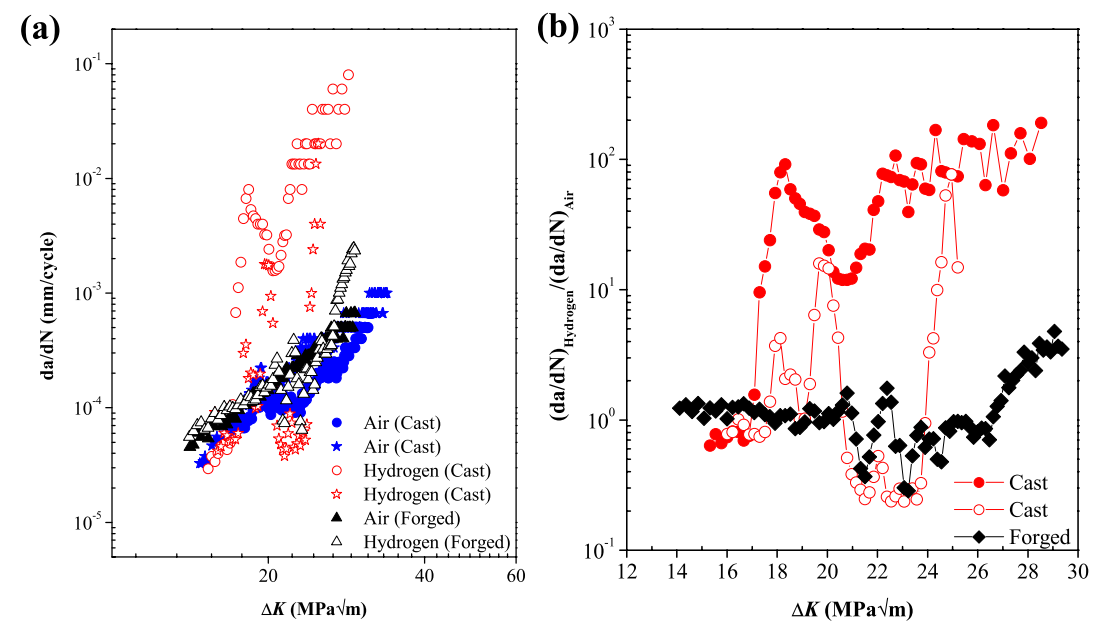

Fig. 10. Comparison of fatigue crack growth behaviour of cast and forged Ti-6Al-4V. (a) Fatigue crack growth rates, and (b) relative effect of hydrogen as a function of $\Delta K$. Forged data are taken from reference [10]. 